\title{
Predicting Team Project Score: It's More about Team Harmony and Less about Individual Performance
}

\author{
Mr. Jeong Hin Chin, University of Michigan
}

Bachelor of Science in Statistics, Statistics Department, College of Literature, Science and the Arts.

\section{Mr. Yuan Gao, University of Michigan}

Herbert Li

Mr. Magel P. Su, California Institute of Technology

Magel P. Su is a PhD student in the Department of Applied Physics and Materials Science at the California Institute of Technology under the direction of Professor Harry Atwater. He has a B.S.E in materials science and engineering and a minor in chemistry from the University of Michigan. At Michigan, he was a member of the Ultrafast Laser - Material Interaction Laboratory and the Engineering Honors Program. He also served as an instructor for several courses including Introduction to Engineering, Introduction to Materials and Manufacturing, and Structural and Chemical Characterization of Materials.

\section{Dr. Robin Fowler, University of Michigan}

Robin Fowler is a lecturer in the Program in Technical Communication at the University of Michigan. She enjoys serving as a "communication coach" to students throughout the curriculum, and she's especially excited to work with first year and senior students, as well as engineering project teams, as they navigate the more open-ended communication decisions involved in describing the products of open-ended design scenarios. 


\title{
Predicting Team Project Score: It's More about Team Harmony and Less about Individual Performance
}

\begin{abstract}
Team-based assignments and other collaborative learning methods are common in undergraduate engineering programs across the world, and they are especially prevalent in first-year introductory engineering courses as well as final-year capstone projects. Team-based learning has been shown in previous studies to improve students' academic achievement, persistence, intrinsic motivation, and attitude toward subject areas compared to more traditional methods of learning, and it can be a powerful tool for increasing self-efficacy and experience by allowing students to define their own roles on teams. However, despite the literature supporting team-based learning, it is not a universally positive experience for all students, particularly in cases where team difficulties may intensify pre-existing inequities in the classroom. Because students composing a team can come from vastly different academic backgrounds with different levels of experience with engineering, a team's overall performance may be linked to the performance of students on individual assignments.
\end{abstract}

In this paper, we investigate how individual student performance is related to overall student team performance in a first-year engineering design-build-test-communicate course. Furthermore, we investigate the relationship between individual students' ratings of their teams and teammates and the scores earned collectively by the team. Specifically, we analyze student responses to weekly team checks, individual student performance ratings as rated by their teammates, and individual student performance on individual class assignments, and compare these metrics to the overall team grades earned by their respective team. The results suggest a positive, though insignificant, trend between teams with more positive weekly team checks and higher overall team grades. We also find a significant trend between teammates who rate each other highly for "producing quality work" and earning higher grades on the team project. Furthermore, we find that individual student performance is not significantly correlated with grades earned on the team project. Finally, we observe a negative, though insignificant, trend between teams with a higher standard deviation of individual student exam performances (bigger spread) and overall team grades. That is, teams with more dispersion in exam performance earn lower grades in this sample. 


\section{INTRODUCTION}

Team-based assignments and other collaborative learning methods are commonly found in undergraduate engineering programs across the world, and they are especially prevalent in first-year introductory engineering courses as well as final-year capstone projects [1-4]. Team-based learning has been shown in previous studies to improve students' academic achievement, persistence, intrinsic motivation, and attitude toward subject areas compared to more traditional methods of learning, and can be a powerful tool for increasing self-efficacy and experience by allowing students to define their own roles on teams [5-10]. Despite the literature supporting team-based learning, it is not a universally positive experience for all students, particularly in cases where team difficulties may intensify pre-existing inequities in the classroom and subsequently the allocation of workload [11-16]. Since teams are often composed of students from a wide variety of academic backgrounds with different levels of engineering experience, it is common for students to worry about the unjust implications of team-based assignments [17-18]. For example, women report higher levels of dissatisfaction from working on teams compared to men [19-20]. While team-based learning encourages students to work with and learn from their peers, it may also result in an environment which pressures students in an unfamiliar environment or encourages pre-existing inequities to grow.

Another major concern from students regarding team-based learning is the idea that team-based learning brings about unfair grading experiences. Specifically, two major concerns are commonly expressed among students: the first concern is that instructors are assigning grades to the team without consideration of the individual contributions of students towards the team deliverable, resulting in an unfair allocation of grades, and conversely, when self- and peer-evaluation is used to determine fair allocation of grades, students are pressured by friends and teammates to manipulate their assessments of achievements [17]. Regarding the first concern, it is commonly observed that students, especially "high-achieving" students, report that team-based learning may affect them negatively academically [21]. Conversely, other students are able to earn higher scores by simply contributing less to the project than their peers [22-25]. Also, it has been reported that these workload inequalities can develop into social interactions which further exacerbate inequalities and lead to higher levels of dissatisfaction on the team [18]. These types of interactions arising from inequitable task allocation on teams can lead to negative changes in student self-efficacy, interest, and experiences in engineering [26].

In order to combat the perceived inequalities expressed by students regarding team-based projects, instructors have introduced and developed techniques to assist in the teamwork process. For example, instructors may provide computer-supported collaborative learning environments to improve peer interactions, or use peer mentors to assist teams throughout the semester. Both 
methods have strongly demonstrated beneficial outcomes in higher education from increased learning gains for students to increased disagreement resolutions for students on the same team [27-35]. However, these methods require either a collaborative infrastructure or collaborative learning space already in place for the instructor to utilize, or recruiting peer mentors, which can be difficult for instructors in large classes common at many universities.

As such, one particular method that many instructors have adopted is using teamwork assessment and support tools to encourage students to rate their teammates and each other [34, 36-37]. Instructors are able to use teamwork assessment/support tools for both large and small classes and tailor these tools for their respective classes without investing large amounts of time. Furthermore, teamwork assessment/support tools can gather large amounts of data from students to achieve multiple goals at once: they allow faculty to access, respond, and use student feedback to understand and support many specific team dynamics and individual students. These tools allow instructors to access student responses to identify "strong" and "weak" teammates (with respects to collaborate team efforts). They also allow instructors to identify teams struggling with the teamwork process so that they can intervene and provide support immediately [38]. Effectively, these tools can be used as formative assessment tools for student dynamics on teams, allowing the instructor to correct team dynamics before they become too problematic. While some instructors perceive peer evaluations gathered from teamwork assessment tools as lacking in reliability compared to instructor evaluations, these concerns are often related to the fact that students are rating themselves and their teammates, and each student has different expectations for their teams, resulting in a wide range of scores for students. However, these concerns can usually be alleviated by providing a rubric/guideline/questionnaire for students to follow when assessing their teammates [38].

In order to elaborate more on these concerns, this paper reports on the responses of students from one section of a first-year, intensive, team-based learning course to a teamwork assessment tool, and how these responses correlated with the academic performances of individual students and their respective teams. The assessment and data analysis work was done by undergraduate research assistants. One author was previously an instructional assistant for the course, and one author is a faculty member serving as an instructor for the course.

\section{RESEARCH QUESTIONS AND METHODS}

In this paper, data previously collected from a first-year design-build-test-communicate team-based learning course is used to address the following overarching research questions:

RQ1: How are students' responses to weekly team checks related to the overall team performance academically? 
RQ2: How does the rating of "producing quality work" that students assign to their teammates relate to the overall team performance academically?

RQ3: How does student performance on individual course assignments relate to the overall team performance academically?

\section{Data Collection}

The data for this study and paper was collected from a first-year team-based learning engineering course at a large public research university using a team assessment tool. The course itself is dominated by a main project in which students spend most of the semester ( 7 weeks) working on the designing, building, and testing of an underwater remotely operated vehicle (ROV) to complete a series of mechanical tasks underwater. As part of a team, students are required to brainstorm and design an ROV capable of completing the required tasks, build the ROV in a machine shop, test the ROV in a large hydrodynamics lab, and communicating their results in both a presentation for the rest of the class and a final report detailing the entire project. Along the way, students are required to participate in progress reports and respond to weekly surveys and teamwork lessons via a teamwork support tool. The students are also supported by two full-time faculty instructors (one technical and one communications instructor), one full-time lab technician, four paid undergraduate instructional assistants who run the lab sections of the course, and 12 voluntary peer mentors (one peer mentor is assigned to each student team).

The data comprises a total of twelve student teams ( $\mathrm{N}=12$ teams) with five students on each team $(\mathrm{N}=60$ students). Teams in this class are assigned by instructors, following a set of guidelines. When faculty are aware of relationships outside of class, students who know each other are not assigned to the same team. Students who live near each other are assigned together, when possible, though instructors avoid assigning a team where all but one single student live near each other. Instructors avoid stranding women or under-represented minority students.

Student responses were pulled from a teamwork support tool being developed by the Center for Academic Innovation at the University of Michigan. For this study, we considered weekly responses to the statement "This team works well together," rated by students individually on a 9-point scale ranging from "Strongly Agree" to "Strongly Disagree". We also looked at peer assessments from the end of the semester, with each student's peer assessment score determined by averaging all of the scores that they received from their teammates. Scores for this assessment were scored on a 9-point scale ranging from "Strongly Agree" to "Strongly Disagree" to the statement "[Teammate's name] produces work of high quality". Note that while these were the 
only responses studied for the purposes of this project, the team assessment tool included more questions and other assignments that students had to complete each week.

Data for students' academic performance was pulled from the course gradebook, which included individual exam scores (two in-class exams, summed, accounting for $25 \%$ of the total course grade) and team scores on project assignments (team scores are shared among all teammates; scores on design reviews [oral] and reports [written] are summed; these assignments account for $4 \%$ of the total course grade). Use of this de-identified data was deemed exempt by the Institutional Review Board [HUM00173623].

Individual exam scores. Students in the class complete two in-class exams, together worth 200 pts $(20 \%$ of the course grade). For this analysis, the two scores were summed to give a single exam score. The exams are designed to test skills required in the overall design project, though some skills (e.g., calculations to predict full scale performance based on test data) are easier to test than others (e.g., cutting PVC). The exams are open-resource, so that they test ability to apply knowledge, not memorization of relevant information. Students can access course materials as well as external resources, though they can not interact with others during the exam. Exam questions test technical ( $\sim 2 / 3$ of the exam) and communication $(\sim 1 / 3$ of the exam) course content. Questions include show-your-work calculations, short-answer, and critique (e.g., given a data table, reformat to follow course communication guidelines).

Team scores. Teams in the class complete a series of design presentations and reports, which together sum to $500 \mathrm{pts}$ ( $50 \%$ of the course grade). For most teams, scores are shared amongst all teammates; students are told that extreme imbalances in effort and work may result in team scores being "scaled" for individuals. In practice, team scores are shared for more than $90 \%$ of teams. Team assignments are scored by both technical and communication faculty; though each assignment's weights may differ, the total score is half technical and half communication.

\section{Team Assessment/Support Tool}

Team assessment information comes from a teamwork tool developed by the authors' institution, in collaboration with one of the authors on the project. More information about this tool is available in [40]. For the purposes of this report, it is important to understand two measures. Weekly, students are asked to complete a 5-item "team health check," which asks students to rate how well the team is handling logistics, sharing ideas, sharing the workload, and working together respectfully, as well as their overall confidence in their ability to complete the project. All of these questions are asked at the team level: that is, while individual students are responding, they do not differentiate responses per teammate but rather answer for the team 
overall. This study looks at the average rating for the most general item, "This team works well together," calculated over all responses at all time points. The second relevant measure is a peer and self assessment, which is administered at a project mid-point and again at the end of the semester. Students rate each teammate and themselves on a variety of questions. This study looks at each student's received "completes quality work" score-- that is, the average score received from peers, averaged across mid-point and final assessments. Self-ratings were excluded for this analysis.

\section{RESULTS}

The first research question addressed was how students' responses to weekly team checks were related to the overall team performance. To address this, Pearson's correlation was used to calculate the relationship between the average weekly student response score to the prompt "This team works well together," and the overall points earned on team assignments. The prompt was scored by students individually on a 9-point Likert scale in response to how well they believed their team collaborated inside and outside of the lab. Figure 1 shows the relationship between the average prompt score ("Team Work Well Score") for each team and the overall team score earned by each team at the end of the semester. Because this analysis is at the team-level, there are only 12 data points in the sample.

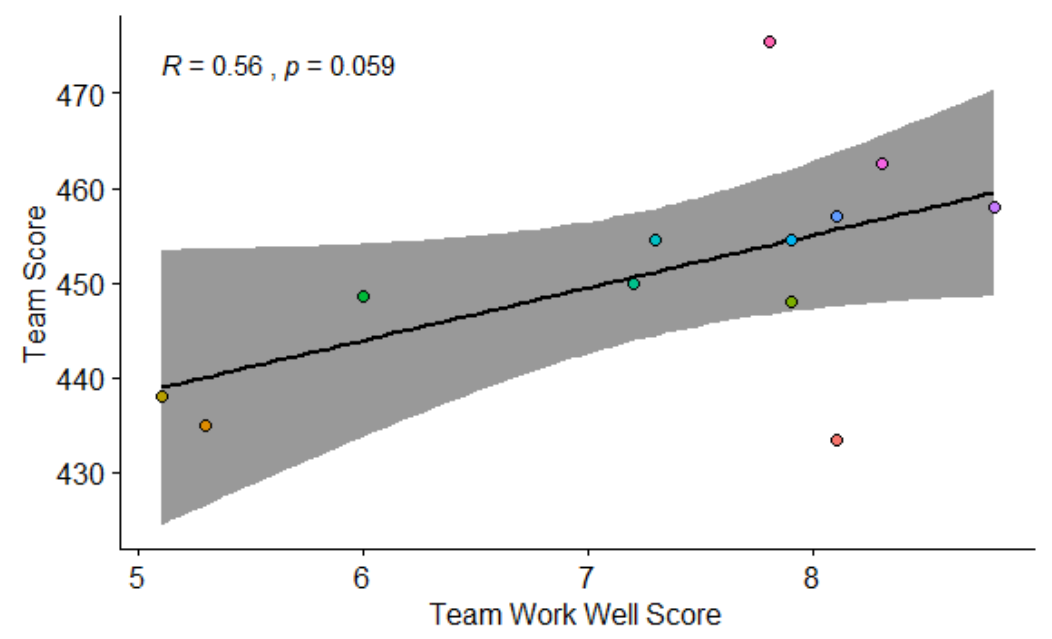

Figure 1. Average "Team Work Well" response score by individual students versus overall team score earned by each team at the end of the semester $(n=12)$. While non-significant, the high $\mathrm{R}$ suggests it is worth exploring this question in a larger sample.

As shown in Figure 1, there is an observed positive relationship between the "Team Work Well" response score and the overall points earned by the team on the project, suggesting that teams in which students reported higher teamwork scores overall performed better than teams in which 
students reported lower teamwork scores. However, while a positive trend is noted, this result was statistically insignificant $(p=0.059)$. Because of the high $\mathrm{R}$ and small sample $(\mathrm{n}=12)$, while we cannot reject the null hypothesis, we believe it is worth collecting more data. However, the direction of the relationship is not clear; it is plausible to imagine that teams receiving high scores are more likely to believe the team is working well together.

To address the second research question, Pearson's correlation was again used to calculate the correlation between students' ratings of their teammates on the prompt "[Teammate's name] produces work of high quality," and the overall points earned by the team on the proect. Once again, the prompt was completed by students individually on a 9-point Likert scale in response to how well they believed teammates produced quality work towards the team deliverables. Figure 2 shows the relationship between the ratings that students received from their teammates ("Students' Quality Work Score") and the overall team score earned by each team at the end of the semester. We report on the scores for all individual students ( $\mathrm{N}=60$ students) to show the range of ratings for each team.

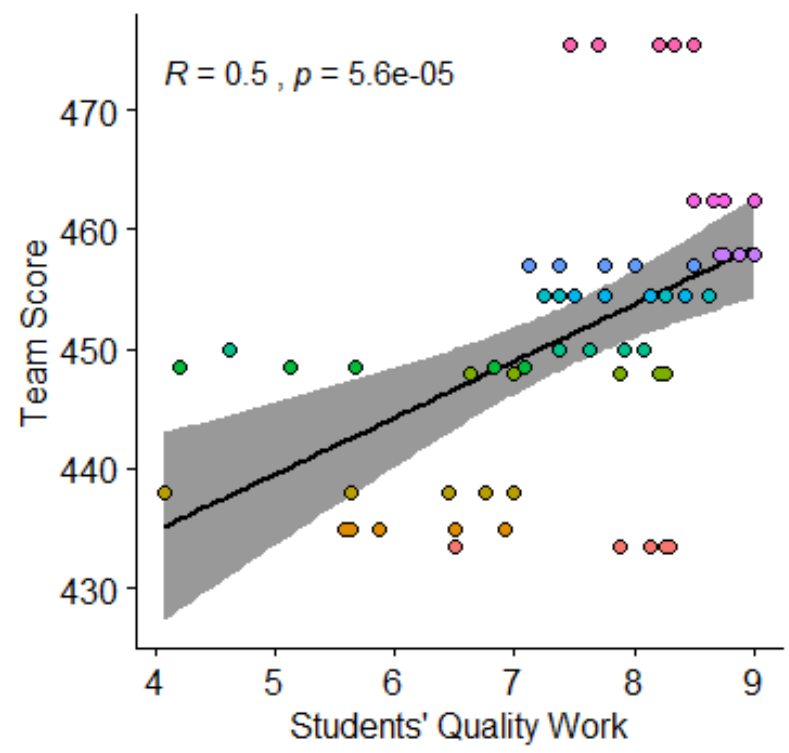

Figure 2. Quality Work ratings that students received from their teammates versus overall team score earned by each team at the end of the semester.

As shown in Figure 2, there is a positive statistically significant $(p<0.05)$ correlation between individual students earning high quality work ratings from their teammates and the overall team score. In general, a team which has a higher average quality work rating among all of the students on the team earned a higher team score at the end of the semester. Furthermore, we can see from the range of ratings earned on individual teams that teams with a larger range of ratings tend to earn lower team scores. 
To address the third research question, how students' individual performance is related to team score, we first calculated Pearson's correlation for students' individual performances versus their overall team performance. Individual student performances were quantified by their summed exam scores. Figure 3 shows the relationship between students' individual exam scores and the overall team score earned by each team at the end of the semester. We report on the scores for all individual students $(\mathrm{N}=60$ students $)$.

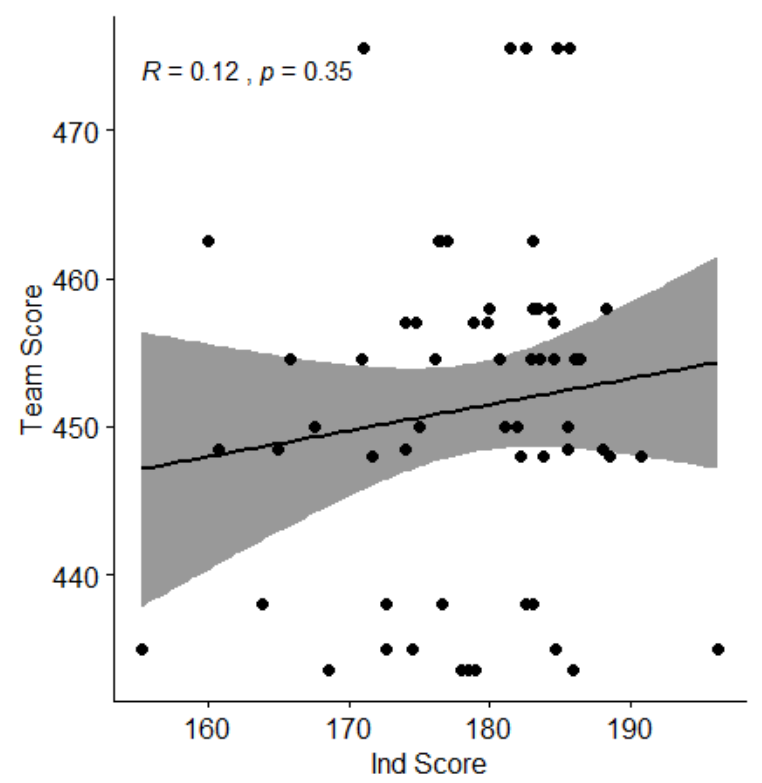

Figure 3. Individual student exam performance versus overall team score earned by each team at the end of the semester.

From Figure 3, we observe that this result is not statistically significant $(p=0.35)$. This result is surprising since we predict students with higher individual exam scores to also perform better on the team score. In this case, it appears that there is no significant correlation between students' individual exam performance and their team score.

Furthermore, we also calculated Pearson's correlation between students' ratings of their teammates on the prompt "[Teammate's name] produces work of high quality," and their individual performance. Figure 4 shows the relationship between the ratings that students received from their teammates ("Students' Quality Work Score") and their individual exam performances. 


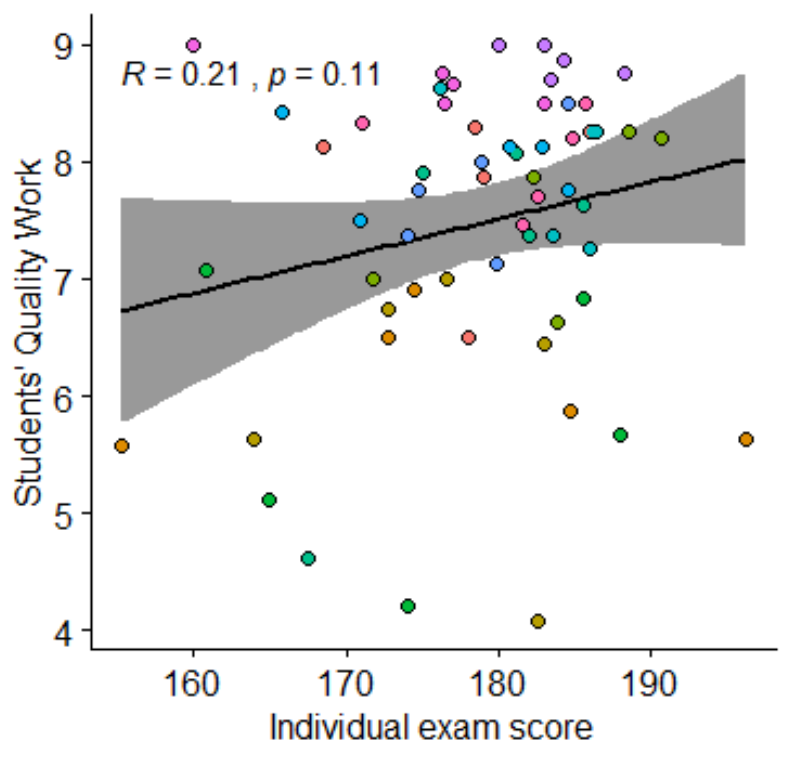

Figure 4. Individual student exam performance versus Quality Work ratings that students received from their teammates.

Once again, there was no significant $(p=0.11)$ correlation between individual student performance and the Quality Work ratings that they received from their teammates. This suggests that students who performed well on individual exams were not perceived to produce better quality work for the team project than students who performed worse on individual exams.

Finally, we calculated Pearson's correlation between the standard deviation of individual exam scores on each team and the overall team score. A team with a higher standard deviation was interpreted as having a wider range in individual student performance. Thus, a team with a higher standard deviation may have more inequality in student performance. Figure 5 shows the relationship between each team's standard deviation for individual student performances and the overall team score. 


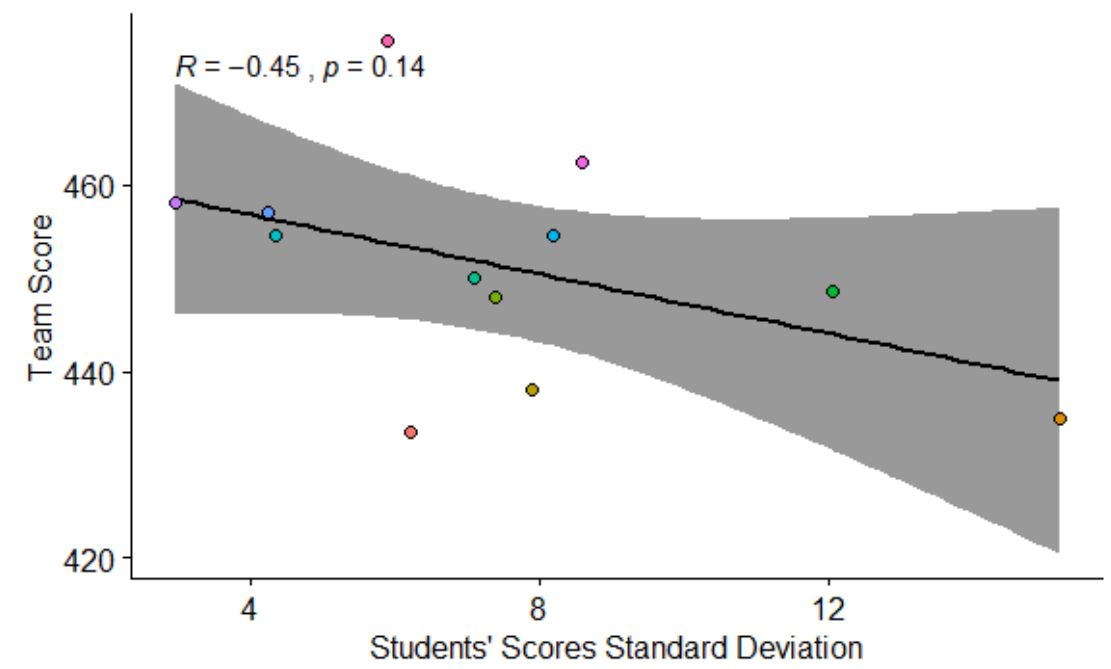

Figure 5. Standard deviation of individual student scores on each team versus overall team score earned by each team at the end of the semester.

Figure 5 shows no significant $(p=0.14)$ correlation between the spread of individual student scores on a particular team, and that respective team's overall score. This suggests that the wider range of individual student performance is not related to the overall score earned by the team.

\section{DISCUSSION}

From the results, we observe that there is no significance between individual student performance and overall team scores. We also observe that there is no significance between the average "Team Work Well" response scores and overall team scores, but there was significance between the Quality Work ratings and overall team scores. We attribute these observations to several reasons.

To discuss the significant trend observed in Figure 2 between Quality Work rating and overall team scores, we see that while some teams had a large range of quality work ratings, no teams had only low quality work ratings among all team members. This suggests that teams with large ranges had higher levels of inequitable task allocation than teams with a low range of ratings. Inequitable task allocation is reported in literature to be one of the common reasons that students report dissatisfaction on team-based learning projects [17-18, 22-26]. As such, higher levels of dissatisfaction on a team may lead to poorer performances due to perceived inequalities. Furthermore, several teams had only one student with a low quality work rating. This suggests that one student on the team was perceived to not be fairly contributing to the team deliverables by the rest of their teammates. Once again, dissatisfaction with the team may have led to lower team scores. 
Another possible explanation for the significance between Quality Work rating and overall team score is that a single student not producing work at a level perceived to be acceptable by the team may cause the overall workload of the other students to increase unfairly, effectively resulting in a four student team. As such, we predict that student teams with a low range of quality work ratings have lower levels of inequitable task allocation resulting in higher satisfaction and higher overall team scores. Conversely, teams with high ranges of quality work ratings (either because one student has a low quality work rating, or the team has a high range as a whole) have higher levels of inequitable task allocation resulting in lower satisfaction and lower overall team scores.

We also observe in Figure 1 that there is no significance between average "Team Work Well" scores and overall team scores. This appears to contrast with the previous result which suggests that higher inequitable task allocation leads to higher dissatisfaction and lower team scores. However, it is possible that a team may work well together socially and allocate tasks equitably, but not be producing quality work as judged by themselves. This interpretation suggests that students are able to successfully differentiate production of quality work and how well the team works together.

We further observe that there is no significant trend between individual student performance and overall team score, individual student performance and Quality Work rating, and spread of individual student performances on a team and overall team score. The first result in Figure 3 suggests that students do not successfully translate individual performance on exams towards performance on team deliverables. Reasons for this unsuccessful transfer of skills can be social (i.e. students who perform well on exams do not work as well with students who perform worse on exams), or it can simply be that these exam scores failed to fully capture the skills that the team deliverables assess. In such a case, the team overall score and individual student exam scores would be assessing different skills and no significant relationship would be expected. Another possible explanation is that some teams which work well may have been more optimal in their task allocation, resulting in every student on the team performing only the tasks that best fit their skillset. Since the exams aim to assess all of the topics that are covered throughout the course, this could result in students performing poorly on the other sections on the exam. This could produce a situation where a team has a high overall score but a low average individual student score across the team.

Figure 4 suggests that students who perform well on exams do not seem to receive higher Quality Work ratings from their teammates compared to students who perform worse on exams. This lends evidence to the suggestion that the exam scores in this study failed to assess the same skills that the team deliverables assessed. 
We observe in Figure 5 no significance between the spread of individual student scores on a team, and the team's overall score. This suggests that teams with a wider distribution of individual exam scores do not perform significantly worse than teams with a narrower distribution of individual exam scores. Since we expect a wider distribution of individual scores to be an indicator of skill inequality on a team, this should lead to a higher level of dissatisfaction on the team and an overall lower team score. However, we do not observe this effect significantly.

Though Figures 1 and 5 show insignificant trends, we note that the trends are all in the expected directions. Figure 1 shows a positive trend between "Team Work Well" score and overall team score and Figure 5 shows a negative trend between the spread of individual student scores on a team, and the team's overall score. This aligns with the idea that higher levels of dissatisfaction leads to lower overall team scores, and vice versa. Though this may be true in this study, we see that this effect does not significantly affect team scores, as seen by the $p$ values reported.

Figures 3 and 4 show little to no trend in any direction. This suggests once again that individual student exam scores by themselves do not predict overall team score. However, as noted previously, the spread of individual exam scores does have a stronger negative trend, suggesting that it is the inequality of skills among students, not the actual skill level of the students, that is a stronger predictor of overall team scores.

It is important to note finally several limitations of this study. First, as suggested previously, exam scores may simply fail to assess the same skills as the team deliverables. Second, it may be that the correlations are flipped: teams which receive higher team scores on deliverables may report higher Quality Work ratings and "Team Work Well” scores because they are more satisfied than teams receiving lower team scores on deliverables. While this issue is unlikely to explain the entire relationship because many of the weekly assessments were given before team scores were given out, it may still explain a portion of the results. Third, instructors may be biased by their perceptions of team cooperation and satisfaction, and by individual student performances in lecture. While it is difficult to predict how this bias may affect the results, it is likely that grades are not scored evenly across all students and teams. Fourth, instructors may apply artificial bounds to team scores, condensing the range of possible scores. In other words, instructors may be reluctant to give a single team a significantly worse grade than the other teams, even if that team's performance was significantly worse than the other teams. A significant trend may be observed by increasing the sample size of sixty students and twelve teams.

These results suggest that while inequitable task allocation and team dissatisfaction may lead to overall lower team scores, the effect in general is insignificant in the case of this first-year 
team-based learning course. The strongest predictor of high team score is the perception that teammates are performing high quality work.

\section{REFERENCES}

[1] R. Seidel, E. Godfrey and others, "Project and team based learning: An integrated approach to engineering education," in 4th ASEE/AaeE Global Colloquium on Engineering Education, 2005.

[2] C. L. Dym, A. M. Agogino, O. Eris, D. D. Frey and L. J. Leifer, "Engineering design thinking, teaching, and learning," Journal of Engineering Education, vol. 94, pp. 103-120, 2005.

[3] K. A. Smith, S. D. Sheppard, D. W. Johnson and R. T. Johnson, "Pedagogies of engagement: Classroom-based practices," Journal of Engineering Education, vol. 94, pp. 87-101, 2005.

[4] D. W. Johnson, R. T. Johnson and K. A. Smith, "Cooperative learning returns to college what evidence is there that it works?," Change: the magazine of higher learning, vol. 30, pp. 26-35, 1998.

[5] K. S. Cockrell, J. A. H. Caplow and J. F. Donaldson, "A context for learning: Collaborative groups in the problem-based learning environment," The Review of Higher Education, vol. 23, pp. 347-363, 2000.

[6] A. Yadav, D. Subedi, M. A. Lundeberg and C. F. Bunting, "Problem-based Learning: Influence on Students 'Learning in an Electrical Engineering Course," Journal of Engineering Education, vol. 100, pp. 253-280, 2011.

[7] D. W. Johnson and others, "Cooperative Learning: Increasing College Faculty Instructional Productivity,” ASHE-ERIC Higher Education Report No. 4, 1991., ERIC, 1991.

[8] L. Springer, M. E. Stanne and S. S. Donovan, "Effects of small-group learning on undergraduates in science, mathematics, engineering, and technology: A meta-analysis," Review of educational research, vol. 69, pp. 21-51, 1999.

[9] D. R. Garrison and J. B. Arbaugh, "Researching the community of inquiry framework: Review, issues, and future directions," The Internet and Higher Education, vol. 10, pp. 157-172, 2007.

[10] R. M. Felder and R. Brent, "Cooperative Learning in Technical Courses: Procedures, Pitfalls, and Payoffs.," 1994. ERIC Document Reproduction Service ED-377038.Available: https://eric.ed.gov/?id=ED377038, Accessed on: March 6, 2018.

[11] R. M. Felder, G. N. Felder, M. Mauney, C. E. Hamrin and E. J. Dietz, "A longitudinal study of engineering student performance and retention. III. Gender differences in student performance and attitudes," Journal of Engineering Education, vol. 84, pp. 151-163, 1995.

[12] B. Linder, M. Somerville, O. Eris and N. Tatar, "Work in Progress - Taking One for the Team: Goal Orientation and Gender-Correlated Task Division," in Frontiers in Education Conference (FIE), 2010 IEEE, 2010. 
[13] S. Ingram and A. Parker, "Gender and modes of collaboration in an engineering classroom: A profile of two women on student teams," Journal of business and technical communication, vol. 16, pp. 33-68, 2002.

[14] L. A. Meadows and D. Sekaquaptewa, "The influence of gender stereotypes on role adoption in student teams," in Proc. 120th ASEE Annual Conf. Exposition, 2013.

[15] L. K. Michaelsen and M. Sweet, "The essential elements of team-based learning," New directions for teaching and learning, vol. 2008, pp. 7-27, 2008.

[16] K. L. Tonso, "The impact of cultural norms on women," Journal of Engineering Education, vol. 85, pp. 217-225, 1996.

[17] L. E. Willcoxson, “'It's not fair!”: Assessing the dynamics and resourcing of teamwork," Journal of Management Education, vol. 30, pp. 798-808, 2006.

[18] K. L. Tonso, "Teams that work: Campus culture, engineer identity, and social interactions," Journal of engineering education, vol. 95, pp. 25-37, 2006.

[19] C. J. Atman, S. D. Sheppard, J. Turns, R. S. Adams, L. N. Fleming, R. Stevens, R. A. Streveler, K. A. Smith, R. L. Miller, L. J. Leifer and others, "Enabling Engineering Student Success: The Final Report for the Center for the Advancement of Engineering Education. CAEE-TR-10-02.," Center for the Advancement of Engineering Education (NJ1), 2010.

[20] R. Fowler, "Demographic Effects on Student-Reported Satisfaction with Teams and Teammates in a First-Year, Team-Based, Problem-Based Course," in 2016 ASEE Annual Conf. Exposition, New Orleans, Louisiana, 2016.

[21] R. Tucker, and N. Abbasi, "Bad attitudes: Why design students dislike teamwork," Journal of learning design, vol. 9, pp. 1-20, 2016.

[22] J. J. Tang, and P. A. Fisher. "High achieving students and their experience of the pursuit of academic excellence," in Proceedings of International Symposium on Education and Psychology, pp. 475-499, 2012.

[23] H. J. Lee, H. Kim, and H. Byun. "Are high achievers successful in collaborative learning? An explorative study of college students' learning approaches in team project-based learning," Innovations in Education and Teaching International, vol. 54, pp. 418-427, 2017.

[24] O. Almatrafi, A. Johri, H. Rangwala, and J. Lester, "Identifying Course Trajectories of High Achieving Engineering Students through Data Analytics," In Proceedings of ASEE, 2016.

[25] R. R. Fowler and M. P. Su, "Gendered Risks of Team-Based Learning: A Model of Inequitable Task Allocation in Project-Based Learning," IEEE Transactions on Education, vol. 61, pp. 312-318, 2018.

[26] J. M. Good, G. Halpin, and G. Halpin, "A promising prospect for minority retention: Students becoming peer mentors," Journal of Negro Education, vol. 69, pp. 375-383, 2001.

[27] S. G. Brainard and L. Carlin, "A six-year longitudinal study of undergraduate women in engineering and science," Journal of Engineering Education, BLAH, 369-375, 1998.

[28] G. Crisp and I. Cruz, "Mentoring college students: A critical review of the literature between 1990 and 2007," Research in Higher Education, 50(6), 525-545, 2009. 
[29] S. Hug, H. Thiry, and P. Tedford, "Learning to love computer science: Peer leaders gain teaching skill, communicative ability and content knowledge in the CS classroom," In Proceedings of the 42nd ACM Technical Symposium on Computer Science Education, pp. 201-206, 2011.

[30] R. L. Jorczak, "An information processing perspective on divergence and convergence in collaborative learning," International Journal of Computer-Supported Collaborative Learning, vol. 6, pp. 207-221, 2011.

[31] L. Lipponen, K. Hakkarainen, and S. Paavola, "Practices and orientations of CSCL," In What we know about CSCL, pp. 31-50. Springer, 2004.

[32] Y. Zhao. "The effects of anonymity on computer-mediated peer review," International Journal of Educational Telecommunications, vol. 4, pp. 311-345, 1998.

[33] T. Connolly, L. M. Jessup, and J. S. Valacich. "Effects of anonymity and evaluative tone on idea generation in computer-mediated groups," Management science, vol. 36, pp. 689-703, 1990. [34] K. Maneeratana and A. Sripakagorn, "Use of CATME for teamwork assessment in engineering projects," ThaiPOD 2009, 2009.

[35] R. Fowler, "Talking teams: Increased equity in participation in online compared to face-to-face team discussions," Computers in Education Journal, vol. 6, pp. 21, $2015 .$.

[36] P. L. Hirsch and A. F. McKenna, "Using reflection to promote teamwork understanding in engineering design education," International Journal of Engineering Education, vol. 24, pp. 377, 2008.

[37] N. Clark, P. Davies, and R. Skeers, "Self and peer assessment in software engineering projects." Proceedings of the 7th Australasian conference on Computing education-Volume 42. Australian Computer Society, Inc., 2005.

[38] H. J. Lee, and C. Lim. "Peer evaluation in blended team project-based learning: what do students find important?" Educational Technology \& Society, vol. 15, pp. 214-225, 2012.

[39] Burdett, Jane, and Brianne Hastie. "Predicting satisfaction with group work assignments." Journal of University Teaching \& Learning Practice 6, no. 1 (2009): 7.

[40] redacted 